\title{
Efficacy and Safety of Early Tracheotomy in Acute Cervical Spinal Cord Injury
}

\author{
Yan Wang ${ }^{1}$, Haijiang Lư ${ }^{2}$, Haijun Teng ${ }^{2}$, Guanxing Cui ${ }^{3}$, Dehong Fan ${ }^{3}$ and Min $\mathrm{Li}^{4}$ \\ ${ }^{1}$ Department of Orthopedic Surgery, Weifang Traditional Chinese Medicine Hospital, Weifang, Shandong, China \\ ${ }^{2}$ Department of Orthopedic Surgery, The 80th Army Hospital of PLA, Weifang, Shandong, China \\ ${ }^{3}$ Department of Orthopedic Surgery, Affiliated Hospital of Weifang Medical Uuiversity, Weifang, Shandong, China \\ ${ }^{4}$ Department of Medical Affairs, The Second Naval Hospital of Southern Theater Command of PLA, Sanya, Hainan, China
}

\begin{abstract}
Objective: To evaluate the clinical efficacy and safety of early tracheotomy versus delayed tracheotomy for patients with cervical spinal cord injury.

Study Design: A descriptive study.

Place and Duration of Study: Department of Orthopedic Surgery, The 80th Army Hospital of PLA, Weifang, Shandong, China, from January 2012 to June 2019.

Methodology: Data of 45 patients with cervical spinal cord injury, who underwent tracheotomy and cervical spine internal fixation at the study place, were retrospectively analysed. Twenty-five patients underwent tracheotomy immediately after cervical spine internal fixation (early tracheotomy group) and 20 patients underwent tracheotomy 3-12 days after cervical spine internal fixation (delayed tracheotomy group). Clinical outcomes and tracheotomy complications were compared between the two groups.

Results: Compared with the delayed tracheotomy, the early tracheotomy significantly reduced the total duration of mechanical ventilation $(p<0.01)$, duration of mechanical ventilation after tracheotomy $(p<0.05)$, duration of indwelling tracheal tube $(p$ $<0.05)$, and hospital stay $(p<0.01)$. There were no significant differences in pneumonia, mortality, and complications related to tracheotomy between the groups. No incision infection for tracheotomy and cervical spine internal fixation were found in all patients.

Conclusion: Compared with delayed tracheotomy, early tracheotomy can significantly reduce the duration of mechanical ventilation, duration of indwelling tracheal tube, and hospital stay. Early tracheotomy did not increase the risk of infection of the cervical spine internal fixation. Therefore, early tracheotomy was beneficial and safe for patients.
\end{abstract}

Key Words: Spinal cord injuries, Tracheotomy, Complications.

How to cite this article: Wang Y, Lu H, Teng H, Cui G, Fan D, Li M. Efficacy and Safety of Early Tracheotomy in Acute Cervical Spinal Cord Injury. J Coll Physicians Surg Pak 2020; 30(09):956-960.

\section{INTRODUCTION}

Cervical spinal cord injury (CSCl) is common in clinical practice and is associated with high morbidity, high mortality, high complication rate, and poor prognosis. ${ }^{1}$ Due to central nervous system damage, cervical spinal cord injury can lead to multiple system dysfunctions. ${ }^{2}$ Among them, respiratory dysfunction has become the most important factor for patient death.,

Correspondence to: Dr. Min Li, Department of Medical Affairs, The Second Naval Hospital of Southern Theater Command of PLA, No. 86 Sanya Bay Road, Tianya District, Sanya, 572000, Hainan, China

E-mail: 13360103023@189.cn

Received: April 13, 2020; Revised: August 23, 2020;

Accepted: September 30, 2020

DOI: https://doi.org/10.29271/jcpsp.2020.09.956
Various airway managements including tracheal intubation, tracheotomy, and mechanical ventilation are essential for patients with $\mathrm{CSCl}^{5}$ Tracheotomy should be performed on patients with recurrent respiratory failure, prolonged mechanical ventilation, or intolerance to tracheal intubation. For patients with $\mathrm{CSCl}$, tracheotomy can improve ventilation, reduce complications of tracheal intubation, increase patient's ventilation tolerance, and facilitate airway care and pulmonary secretion clearance ${ }^{6-10}$ However, tracheotomy is an invasive operation, the timing of tracheotomy for patients with $\mathrm{CSCl}$ remains controversial. ${ }^{11-13}$ There are no strict objective criteria for the timing of tracheotomy at present. ${ }^{11,13}$

The aim of this study was to evaluate the clinical efficacy and safety of early tracheotomy (immediately after spine fixation) versus delayed tracheotomy (3-12 days after fixation).

\section{METHODOLOGY}

This study was approved by the Ethical Committee of the $80^{\text {th }}$ Army Hospital of PLA. Clinical data of 45 patients with acute 
$\mathrm{CSCl}$, who underwent tracheotomy and cervical spine internal fixation in this hospital from January 2012 to June 2019, were retrospectively analysed. Clinical records with respiratory diseases, such as chronic bronchitis, chronic obstructive pulmonary disease and asthma, other injuriessuch asintracranial haemorrhage, brain contusion and lung injury, and patients who gave up treatment or were transferred, were excluded. Finally, the clinical data of 45 patients with $\mathrm{CSCl}$, who underwent tracheotomy and cervical spine internal fixation at the hospital, was compared for the prognosis between early tracheotomy (tracheotomy performed immediately after cervical spine internal fixation) and delayed tracheotomy (tracheotomy performed 3-12 days after cervical spine internal fixation) for patients with CSCl. The decision of tracheotomy to a patient was made by either the physicians in this primary unit or in consultation with the physicians in the ICU, based on the patient's age, previous diseases, degree of injury, injury levels, respiratory strength, cough strength, blood gas analysis results, and mechanical ventilation evaluation. ${ }^{5,14}$ It was especially considered for those with high complete cervical spinal cord injury; oxygen saturation is continuously less than $90 \%$; considerable sputum secretions and weak cough strength needed an artificial airway for sputum excretion; those expected to require prolonged mechanical ventilation, and those who underwent orotracheal intubation, and failed to wean from the ventilator after repeated attempts. Tracheotomy performed immediately after cervical spine internal fixation in the operating room was early tracheotomy. While tracheotomy performed 3-12 days after cervical spine internal fixation was defined as delayed tracheotomy.

The degree of CSCI was assessed by ASIA standards. The level of $\mathrm{CSCl}$ was based on the highest injury segment of the cervical spinal cord indicated by MRI. The following clinical parameters were recorded: total duration of mechanical ventilation, duration of mechanical ventilation after tracheotomy, duration of indwelling tracheal tube, hospital stay, pneumonia, mortality, incision infection of anterior cervical spine internal fixation, and tracheotomy complications. The diagnosis of pneumonia required two or more serial chest radiographs of new or progressive and persistent infiltrate and at least two of the following criteria: (1) temperature $>38^{\circ} \mathrm{C}$ or $<35.5^{\circ} \mathrm{C}$; (2) leukocytosis ( $>12000 \mathrm{WBC} / \mathrm{mm}^{3}$ ) or leukopenia $\left(<4000 \mathrm{WBC} / \mathrm{mm}^{3}\right.$ ); (3) new onset of purulent bronchial secretions or change in its character. ${ }^{15}$ The complications of tracheotomy referred to postoperative haemorrhage, subcutaneous emphysema, tracheal stenosis, incision infection, tracheomalacia, and tracheoesophageal fistula. Tracheal stenosis referred to airway stenosis caused by granulomatosis or concentric stenosis; and was diagnosed by an otolaryngologist based on clinical symptoms (wheezing and dyspnoea) and confirmed by laryngoscopy or bronchoscopy. Patients were followed up 3, 6, and 12 months after surgery, and oncea yearthereafter.
Continuous variables were expressed as mean \pm standard deviation (SD) and median (inter-quartile range, IQR). Categorical variables were expressed as numbers and percentages. The 1-Sample Kolmogorov-Smirnov test was used to test the distribution of continuous variables. The two groups were compared with the Student's t-test or Mann-Whitney Utest for continuous variables, and the Chi-square test or Fisher's exact test for categorical variables. Statistical analysis was performed with SPSS 21 software. The value of $p \leq 0.05$ was considered to be statistically significant.

\section{RESULTS}

Clinical records of 45 patients were included, including 32 (71.1\%) males and 13 (28.9\%) females, and the mean age was 50.02 years (ranging from 26 to 69 years). The mean follow-up duration was 15.07 months with a range of 3 to 36 months. The time from cervical spine internal fixation to tracheotomy was $7.1 \pm 2.25$ days in delayed tracheotomy group. There were no significant differences in age, gender, cause of injury, ASIA classification, injury level, surgical approach, and follow-up duration between the two groups $(p>0.05)$. Table I shows the demographic data in early tracheotomy group and delayed tracheotomy group.

Table II shows the clinical outcomes of patients in early tracheotomy group and delayed tracheotomy group. Compared with the delayed tracheotomy, the early tracheotomy significantly reduced the total duration of mechanical ventilation $(p=0.001)$, duration of mechanical ventilation after tracheotomy $(p=0.011)$, duration of indwelling tracheal tube $(p=0.011)$, and hospital stay $(p=0.001)$. There were no significant differences in pneumonia rate $(p=0.161)$ and mortality rate $(p=0.192)$. No incision infection of anterior cervical spine internal fixation was found in either group.

Table III shows the complications related to tracheotomy in early tracheotomy group and delayed tracheotomy group. There werenosignificant differencesin postoperativehaemorrhage $(p=0.577)$, subcutaneous emphysema $(p=0.577)$, and tracheal stenosis ( $p=0.080$ ) between the two groups. No incision infection, tracheomalacia, and tracheoesophageal fistula were found in either group.

\section{DISCUSSION}

Patients with cervical spinal cord injury often have respiratory dysfunction or even respiratory failure due to respiratory muscle paralysis. About $21-77 \%$ of patients require tracheotomy and rely on mechanical ventilation to varying degrees. ${ }^{16}$ Compared with tracheal intubation, tracheotomy can reduce dead cavity ventilation and work of breathing, benefit to airway care and pulmonary secretion clearance, and it can reduce laryngeal injury, sedation time, and increase patient comfort. ${ }^{6-10}$ However, there are no strict standards for tracheotomy indications, and no clear criteria for tracheotomy timing. ${ }^{11-13}$ 
Table I: Comparison of demographic data between early tracheotomy group and delayed tracheotomy group.

\begin{tabular}{|l|c|c|c|}
\hline \multirow{2}{*}{ Characteristics } & \multicolumn{2}{|c|}{ Tracheotomy } & \multirow{2}{*}{-value } \\
\cline { 2 - 4 } & Early & Delayed & \\
\hline Patients $(n)$ & 25 & 20 & \\
\hline Mean age (years) & $51.04 \pm 8.71$ & $48.75 \pm 10.42$ & 0.426 \\
\hline Gender $(n)$ & & & 0.745 \\
\hline Male & $17(68 \%)$ & $15(75 \%)$ & \\
\hline Female & $8(68 \%)$ & $5(25 \%)$ & \\
\hline Cause of injury $(n)$ & & & 0.915 \\
\hline Traffic accidents & $13(52 \%)$ & $12(60 \%)$ & \\
\hline Fall injuries & $8(32 \%)$ & $6(30 \%)$ & \\
\hline Blunt traumas & $4(16 \%)$ & $2(10 \%)$ & \\
\hline ASIA classification $(n)$ & & & 0.626 \\
\hline Grade A & $15(60 \%)$ & $9(45 \%)$ & \\
\hline Grade B & $6(24 \%)$ & $7(35 \%)$ & \\
\hline Grade C & $4(16 \%)$ & $3(15 \%)$ & \\
\hline Grade D & $0(0 \%)$ & $1(5 \%)$ & \\
\hline Injury level $(n)$ & & & 0.872 \\
\hline C1-2 & $3(12 \%)$ & $2(10 \%)$ & \\
\hline C3-5 & $20(80 \%)$ & $15(75 \%)$ & \\
\hline C6-7 & $2(8 \%)$ & $3(15 \%)$ & \\
\hline Surgical approach $(n)$ & & & 0.787 \\
\hline Anterior & $14(56 \%)$ & $12(60 \%)$ & \\
\hline Anterior-posterior & $11(44 \%)$ & $8(40 \%)$ & \\
\hline Follow-up & $12(6-12)$ & $12(12-24)$ & 0.163 \\
\hline
\end{tabular}

Table II: Comparison of clinical outcomes between early tracheotomy group and delayed tracheotomy group.

\begin{tabular}{|l|c|c|c|}
\hline \multirow{2}{*}{ Variable } & \multicolumn{2}{|c|}{ Tracheotomy } & \multirow{2}{*}{-value } \\
\cline { 2 - 4 } & Early & Delayed & \\
\hline $\begin{array}{l}\text { Total duration of mechanical } \\
\text { ventilation (days) }\end{array}$ & $15.68 \pm 6.82$ & $22.50 \pm 5.69$ & 0.001 \\
\hline $\begin{array}{l}\text { Duration of mechanical } \\
\text { ventilation after tracheotomy } \\
\text { (days) }\end{array}$ & $14.36 \pm 6.22$ & $18.70 \pm 4.28$ & 0.011 \\
\hline $\begin{array}{l}\text { Duration of indwelling tracheal } \\
\text { tube (d) }\end{array}$ & $18.04 \pm 5.05$ & $21.85 \pm 4.43$ & 0.011 \\
\hline Hospital stay (days) & $32.36 \pm 6.76$ & $41.00 \pm 8.93$ & 0.001 \\
\hline Pneumonia (n, \%) & $11(44 \%)$ & $13(65 \%)$ & 0.161 \\
\hline Mortality (n, \%) & $0(0 \%)$ & $2(10 \%)$ & 0.192 \\
\hline $\begin{array}{l}\text { Incision infection of anterior } \\
\text { cervical spine internal fixation } \\
\text { (n, \%) }\end{array}$ & $0(0 \%)$ & $0(0 \%)$ & - \\
\hline
\end{tabular}

According to several authors, early tracheotomy is beneficial to patients. Flanagan et al. ${ }^{11}$ found that early tracheotomy (within 7 days of orotracheal intubation) can significantly reduce the duration of mechanical ventilation, duration of indwelling tracheal tube, and ICU stay compared with late tracheotomy (after 7 days of orotracheal intubation). ${ }^{11}$ They pointed out that regardless of the severity and level of $\mathrm{CSCl}$, early tracheotomy can improve respiratory outcomes of patients without increasing the incidence of complications. ${ }^{11}$ Romero et al. ${ }^{17}$ also found that early tracheotomy (within 7 days of orotracheal intubation) can reduce the duration of mechanical ventilation, ICU stay, and complications of long-term intubation. ${ }^{17}$ They recommend early tracheotomy for patients with $\mathrm{CSCl}$ who were likely to require prolonged mechanical ventilation. ${ }^{17}$ Guirgis et al. ${ }^{18}$ pointed out that early tracheotomy (within 7 days after injury) can reduce the duration of mechanical ventilation, and it can reduce the mortality of patients with high $\mathrm{CSCl} .{ }^{18}$

Table III: Comparison of tracheotomy complications between early tracheotomy group and delayed tracheotomy group.

\begin{tabular}{|l|c|c|c|}
\hline \multirow{2}{*}{ Variable } & \multicolumn{2}{|c|}{ Tracheotomy } & \multirow{2}{*}{ p-value } \\
\cline { 2 - 4 } & Early & Delayed & \\
\hline Total complications $(\mathrm{n}, \%)$ & $2(8 \%)$ & $7(35 \%)$ & 0.057 \\
\hline Postoperative haemorrhage $(\mathrm{n})$ & $1(4 \%)$ & $2(10 \%)$ & 0.577 \\
\hline Subcutaneous emphysema $(\mathrm{n})$ & $1(4 \%)$ & $2(10 \%)$ & 0.577 \\
\hline Tracheal stenosis $(\mathrm{n})$ & $0(0 \%)$ & $3(15 \%)$ & 0.080 \\
\hline Incision infection $(\mathrm{n})$ & $0(0 \%)$ & $0(0 \%)$ & - \\
\hline Tracheomalacia $(\mathrm{n})$ & $0(0 \%)$ & $0(0 \%)$ & - \\
\hline Tracheoesophageal fistula $(\mathrm{n})$ & $0(0 \%)$ & $0(0 \%)$ & - \\
\hline
\end{tabular}

Different from their division of tracheotomy, it is found here that early tracheotomy can significantly reduce the duration of mechanical ventilation, duration of indwelling tracheal tube, and hospital stay compared with delayed tracheotomy. However, there were no significant differences in pneumonia, mortality, and tracheotomy complications between the two groups. Moscovicietal. ${ }^{19}$ found it was the changes of respiratory mechanics by which that tracheotomy promoted weaning from the ventilator.

The incidence of pneumonia was high in both groups, reaching $44 \%$ and $65 \%$, respectively. Ventilator-associated pneumonia (VAP) is one of the common and serious complications during mechanical ventilation. ${ }^{20}$ Although early tracheotomy significantly reduced duration of mechanical ventilation, it didn't significantly reduce pneumonia compared with delayed tracheotomy. For these patients, infection was actively fought and patient were given nutritional support. All patients were successfully weaned from the ventilator and the pneumonia were cured or improved when discharged. Two deaths during follow-up were recorded in the delayed tracheotomy group; of which, one death was due to pneumonia and respiratory failure, and another death due to pressure ulcers caused by improper nursing. Moreover, no death was reported in the early tracheotomygroup. However, the difference was not statistically significant. Considering the small sample size, a study with a larger sample size is needed to investigate whether early tracheotomy can reduce the mortality.

When planning surgery, a common concern is whether tracheotomy will affect cervical surgery because the incision for tracheotomy is close to; or even the sameas theincision foranterior cervical spine internal fixation. The former is a clean-contaminated wound while the latter is a clean wound. Cervical internal fixation surgery requires the placement of internal fixation devices. Once infected, it is difficult to control and may cause serious central nervous system infections. For this reason, some scholars accepted orotracheal intubation during perioperative period. But orotracheal intubation cannot be retained for a longer time. Orotracheal intubation for 8 days can result in a high rate of laryngeal injury $(83 \%){ }^{21}$ Lozano et al. ${ }^{22}$ performed early tracheotomy within 4 days after anterior 
cervical fusion. They did not found anterior cervical surgical wound or deep tissue infections. For patients who have undergone tracheotomy before anterior cervical surgery, Northrup et al. ${ }^{23}$ also did not find evidences of cervical soft tissue or bony infection after surgery. Even Galeiras et al. ${ }^{24}$ suggested that the performance of tracheotomy before or immediately after anterior cervical spine fixation was associated with a low risk of infection of the anterior cervical surgical wound. In the present study, no one encountered anterior cervical surgical wound or deep tissue infections.

Therefore, it is believed that tracheotomy does not increase the risk of infection of the anterior cervical spine internal fixation as long as the two incisions and the skin between the two incisions are well-designed and carefully prepared.

No incision infection, tracheomalacia and tracheoesophageal fistula related to tracheotomy were found among the included 45 patients. Three patients with tracheotomy presented with postoperative bleeding oozing from the vein. Two of these patients were treated with a pressure dressing for homeostasis, and the third patient was treated with wound suture and pressure dressing for homeostasis. It is believed that careful intraoperative hemostasis can effectively reduce postoperative haemorrhage. Subcutaneous emphysema occurred in three patients. One exhibited spontaneous resorption. In the other two patients, emphysema subsided after air evacuation via thick needles. Tracheal stenosis is a common late complication of tracheotomy. The frictional stimulation of the tracheal tube, abnormal wound healing with excess granulation tissue formation, wound sepsis, and excessive cartilage damage are important causes of tracheal stenosis after tracheotomy. ${ }^{25}$

In summary, the authors retrospectively analysed the clinical data of patients with $\mathrm{CSCl}$, who underwent tracheotomy in the past 7 years, and compared the clinical efficacy and security between early tracheotomy and delayed tracheotomy for patients with $\mathrm{CSCl}$. Early tracheotomy has many advantages. This study provides new ideas for the airway management for patients with $\mathrm{CSCl}$. However, this study is a retrospective single-centre study. Limitations such as small sample size and bias are unavoidable. Multicentre, large-sample-size randomised controlled trials should be conducted in the future.

\section{CONCLUSION}

Compared with delayed tracheotomy, early tracheotomy can significantly reduce the duration of mechanical ventilation, duration of indwelling tracheal tube, and hospital stay. Early tracheotomy did not increase the risk of infection of the cervical spine internal fixation surgery. Early tracheotomy is a safe and effective choice for patients with cervical spinal cord injury, who need tracheotomy.

\section{ETHICALAPPROVAL:}

This study was approved by the Ethical Committee of The $80^{\text {th }}$ Army Hospital of PLA.

\section{PATIENTS' CONSENT:}

Not applicable as it is a retrospective study for clinical records.
Moreover, patient identifiers were removed before data analysis for confidentiality.

\section{CONFLICT OF INTEREST:}

Authors declared no conflict of interest.

\section{AUTHORS' CONTRIBUTION:}

YW: Literature search, manuscript writing, result interpretation and discussion.

HL, HT: Data collection and analysis and manuscript drafting.

GC, DF: Research design and conception, supervised study and revalidated data.

ML: Revised critically for important content, final manuscript preparation, proofreading, final approval, and overall coordination.

YW, HL, HT: Contributed equally to this study.

All authors approved final version of the manuscript.

\section{REFERENCES}

1. Spinal Cord Injury (SCI) 2016: Facts and figures at a glance. J Spinal Cord Med 2016; 39(4):493-4. doi: 10.1080/ 10790268.2016.1210925.

2. Stein DM, Menaker J, McQuillan K, Handley C, Aarabi B, Scalea TM. Risk factors for organ dysfunction and failure in patients with acute traumatic cervical spinal cord injury. Neurocritical care 2010; 13(1):29-39. doi: 10.1007/ s12028-010-9359-9.

3. Berney S, Bragge P, Granger C, Opdam H, Denehy L. The acute respiratory management of cervical spinal cord injury in the first 6 weeks after injury: A systematic review. Spinal cord 2011; 49(1):17-29. doi: 10.1038/sc.2010.39.

4. Hayashi T, Fujiwara Y, Sakai H, Kubota K, Kawano O, Mori E, et al. The time course of dysphagia following traumatic cervical spinal cord injury: A prospective cohort study. Spinal cord 2020; 58(1):53-7. doi: 10.1038/s41393019-0347-4.

5. Hou YF, Lv Y, Zhou F, Tian Y, Ji HQ, Zhang ZS, et al. Development and validation of a risk prediction model for tracheostomy in acute traumatic cervical spinal cord injury patients. Eur Spine J 2015; 24(5):975-84. doi: 10.1007/ s00586-014-3731-y.

6. Jaeger JM, Littlewood KA, Durbin CG, Jr. The role of tracheostomy in weaning from mechanical ventilation. Respiratory care 2002; 47(4):469-80; discussion 81-2. PubMed PMID: 11929618.

7. Cosortium for spinal cord M. respiratory management following spinal cord injury: A clinical practice guideline for health-care professionals. J Spinal Cord Med 2005; 28(3):259-93. doi: 10.1080/10790268.2005.11753821.

8. Brown R, DiMarco AF, Hoit JD, Garshick E. Respiratory dysfunction and management in spinal cord injury. Respiratory care 2006; 51(8):853-68; discussion 69-70. PubMed PMID: 16867197. Pubmed Central PMCID: PMC2495152. Epub 2006/07/27. eng.

9. Adly A, Youssef TA, El-Begermy MM, Younis HM. Timing of tracheostomy in patients with prolonged endotracheal intubation: A systematic review. Eur Arch Otorhino-laryngol 2018; 275(3):679-90. PubMed PMID: 29255970. 
10. Tai HP, Lee DL, Chen CF, Huang YT. The effect of tracheostomy delay time on outcome of patients with prolonged mechanical ventilation: A STROBE-compliant retrospective cohort study. Medicine 2019; 98(35):e16939. doi: 10.1097/MD.0000000000016939.

11. Flanagan CD, Childs BR, Moore TA, Vallier HA. Early tracheostomy in patients with traumatic cervical spinal cord injury appears safe and may improve outcomes. Spine 2018; 43(16):1110-6.

12. Badaoui R, Thiel V, Perret C, Popov I, Dupont H. Bilateral pneumothorax, cervicofacial and mediastinal emphysema after surgical tracheostomy. Annales francaises d'anesthesie et de reanimation 2013; 32(10):718-20. doi: 10.1016/j.annfar.2013.07.815.

13. Seidl RO, Wolf D, Nusser-Muller-Busch R, Niedeggen A. Airway management in acute tetraplegics: A retrospective study. Eur Spine J 2010; 19(7):1073-8. doi: 10.1007/ s00586-010-1328-7.

14. Leelapattana P, Fleming JC, Gurr KR, Bailey SI, Parry N, Bailey CS. Predicting the need for tracheostomy in patients with cervical spinal cord injury. J trauma acute care surgery 2012; 73(4):880-4. doi: 10.1097/TA.0b013e318251fb34.

15. Horan TC, Andrus M, Dudeck MA. CDC/NHSN surveillance definition of health care-associated infection and criteria for specific types of infections in the acute care setting. Am J Infec Contr 2008; 36(5):309-32. DOI: 10.1016/j.ajic. 2008.03.002

16. Branco BC, Plurad D, Green DJ, Inaba K, Lam L, Cestero R, et al. Incidence and clinical predictors for tracheostomy after cervical spinal cord injury: A National Trauma Databank review. J Trauma 2011; 70(1):111-5. doi: 10.1097/TA.0b013e3181d9a559.

17. Romero J, Vari A, Gambarrutta C, Oliviero A. Tracheostomy timing in traumatic spinal cord injury. European spine journal : Official publication of the European spine society, the European spinal deformity society. and the European section of the cervical spine research society 2009; 18(10): 1452-7.
18. Guirgis AH, Menon VK, Suri N, Chatterjee N, Attallah E, Saad MY, et al. Early Versus Late Tracheostomy for Patients with High and Low Cervical Spinal Cord Injuries. Sultan Qaboos University Med J 2016; 16(4):e458-e3. doi: 10.18295/squmj.2016.16.04.009.

19. Moscovici da Cruz V, Demarzo SE, Sobrinho JB, Amato MB, Kowalski LP, Deheinzelin D. Effects of tracheotomy on respiratory mechanics in spontaneously breathing patients. European respiratory j 2002; 20(1):112-7. doi: 10.1183/ 09031936.02 .01342001$.

20. Bassi GL, Ferrer M, Marti JD, Comaru T, Torres A. Ventilatorassociated pneumonia. Seminars Respirat Critical Care Med 2014; 35(4):469-81. PubMed PMID: 25111643.

21. Brodsky MB, Levy MJ, Jedlanek E, Pandian V, Blackford B, Price $C$, et al. Laryngeal injury and upper airway symptoms after oral endotracheal intubation with mechanical ventilation during critical care: A systematic review. Critical Care Medicine 2018; 46(12):2010-7. doi: 10.1097/CCM. 0000000000003368.

22. Lozano CP, Chen KA, Marks JA, Jenoff JS, Cohen MJ, Weinstein MS. Safety of early tracheostomy in trauma patients after anterior cervical fusion. J Trauma Cute Care Surgery 2018; 85(4):741-6. doi: 10.1097/TA.0000000 000002045.

23. Northrup BE, Vaccaro AR, Rosen JE, Balderston RA, Cotler JM. Occurrence of infection in anterior cervical fusion for spinal cord injury after tracheostomy. Spine 1995; 20(22):2449-53. doi: 10.1097/00007632-19951100100014.

24. Galeiras R, Mourelo M, Bouza MT, Seoane MT, Ferreiro ME, Montoto $A$, et al. Risk Analysis Based on the Timing of Tracheostomy Procedures in Patients with Spinal Cord Injury Requiring Cervical Spine Surgery. World Neurosurgery 2018; 116:e655-e61. doi: 10.1016/j. wneu.2018.05.065.

25. Zias N, Chroneou A, Tabba MK, Gonzalez AV, Gray AW, Lamb CR, et al. Post tracheostomy and post intubation tracheal stenosis: Report of 31 cases and review of the literature. BMC Pul Med 2008; 8:18. 